\title{
Analytical variables influencing the performance of a miRNA based laboratory assay for prediction of relapse in stage I non-small cell lung cancer (NSCLC)
}

Jesper Dahlgaard ${ }^{1,5^{*}}$, Wiktor Mazin ${ }^{1}$, Thomas Jensen $^{1}$, Mette Pøh $^{3,4}$, Wiam Bshara ${ }^{6}$, Anker Hansen ${ }^{1}$, Eric Kanisto ${ }^{2}$, Stephen Jacques Hamilton-Dutoit ${ }^{5}$, Olfred Hansen ${ }^{3}$, Henrik Hager ${ }^{5}$, Henrik J Ditzel ${ }^{3,4}$, Sai Yendamuri ${ }^{2}$ and Steen Knudsen ${ }^{1}$

\begin{abstract}
Background: Laboratory assays are needed for early stage non-small lung cancer (NSCLC) that can link molecular and clinical heterogeneity to predict relapse after surgical resection. We technically validated two miRNA assays for prediction of relapse in NSCLC. Total RNA from seventy-five formalin-fixed and paraffin-embedded (FFPE) specimens was extracted, labeled and hybridized to Affymetrix miRNA arrays using different RNA input amounts, ATP-mix dilutions, array lots and RNA extraction- and labeling methods in a total of 166 hybridizations. Two combinations of RNA extraction- and labeling methods (assays I and II) were applied to a cohort of 68 early stage NSCLC patients.

Results: RNA input amount and RNA extraction- and labeling methods affected signal intensity and the number of detected probes and probe sets, and caused large variation, whereas different ATP-mix dilutions and array lots did not. Leave-one-out accuracies for prediction of relapse were $63 \%$ and $73 \%$ for the two assays. Prognosticator calls ("no recurrence" or "recurrence") were consistent, independent on RNA amount, ATP-mix dilution, array lots and RNA extraction method. The calls were not robust to changes in labeling method.

Conclusions: In this study, we demonstrate that some analytical conditions such as RNA extraction- and labeling methods are important for the variation in assay performance whereas others are not. Thus, careful optimization that address all analytical steps and variables can improve the accuracy of prediction and facilitate the introduction of microRNA arrays in the clinic for prediction of relapse in stage I non-small cell lung cancer (NSCLC).
\end{abstract}

\section{Background}

Early stage non-small cell lung (NSCLC) cancer is characterized by both clinical and molecular genetic heterogeneity with five-year recurrence and survival rates of $50 \%$ and $73 \%$ respectively [1]. Although several randomized studies have been performed, the use of adjuvant chemotherapy for stage I NSCLC still is controversial [2] and surgical resection remains the primary treatment for this disease.

\footnotetext{
* Correspondence: jesperdahlgaard@post.au.dk

${ }^{1}$ Medical Prognosis Institute, Venlighedsvej 1, 2970 Hørsholm, Denmark Full list of author information is available at the end of the article
}

However, in spite of tumor heterogeneity, new techniques in molecular profiling [3-5] can supplement clinical and pathologic observations and help to identify patients with a particularly poor prognosis. This can be useful both for intensified follow-up and for administering therapy specifically to patients at a high risk of recurrence [6].

In this study, we performed global microarray expression profiling targeting several small non-coding RNA species including microRNAs (miRNAs). MicroRNAs are small noncoding RNAs of approximately 18-25 nucleotides in length that regulate gene expression at the post transcriptional level by base pairing with

\section{C) Biomed Central}


mRNA, leading to either translational repression [7], or mRNA degradation [8-10]. MicroRNAs have been estimated to regulate up to $30 \%$ of all human genes [11], and frequently reside in cancer associated genomic regions [12]. Deregulation of miRNA expression plays a direct role in oncogenesis, and in differentiation and progression in cancer, in part because deregulation can change the expression of oncogenes and tumour suppressor genes [13]. Strong deregulation of miRNA expression has been seen in several forms of cancer, including lung carcinoma [4], and several studies have suggested that miRNA profiling can be used for prognostication in lung cancer [3-6].

The enhanced stability of microRNAs in contrast to mRNAs, allow expression profiling in routinely stored formalin-fixed and paraffin-embedded (FFPE) specimens, including samples that are more than ten years old [14]. Large FFPE archives exist in diagnostic pathology departments throughout the world. When linked to clinical data, they represent an invaluable biobank resource for exploring the association between molecular changes in tumors and clinical endpoints such as relapse or survival after surgery. Furthermore in the case of early stage NSCLC, FFPE specimens will be available for most patients. Therefore, it is realistic to use miRNAs and non-coding RNAs as biomarkers for prognosis in stage I NSCLC, once a prognostic signature has been clinically validated.

In order to reach this goal, carefully conducted studies are needed $[15,16]$, incorporating well defined experimental procedures that may eventually lead to the development of clinically validated applications allowing for individual treatment strategies in early stage NSCLC. Previously, the Microarray Quality Control (MAQC) study [17] focused on the entire process from sample handling, through laboratory and assay conditions, to data normalization and bioinformatics. This demonstrated the scope and significant potential of microarray technology for the clinic [18] when performed under careful and well-defined experimental conditions.

In this study, we compared two laboratory assays for prognostication in stage I NSCLC based on miRNA profiling in FFPE tissue specimens. To perform an objective evaluation [16], of the different reagents, array products and protocols we examined several analytical conditions (figure 1) including: i) 7 different RNA input amounts using one RNA preparation of a single tumor specimen, ii) three different ATP-mix dilutions using two RNA preparations of two tumor specimens, iii) two different array lot numbers using one RNA preparation of a single tumor specimen, iv) two different $R N A$ extraction kits using eight RNA preparations of four tumor specimens, and, v) two different RNA labeling kits using four RNA preparations of four tumor specimens in 8 labeling

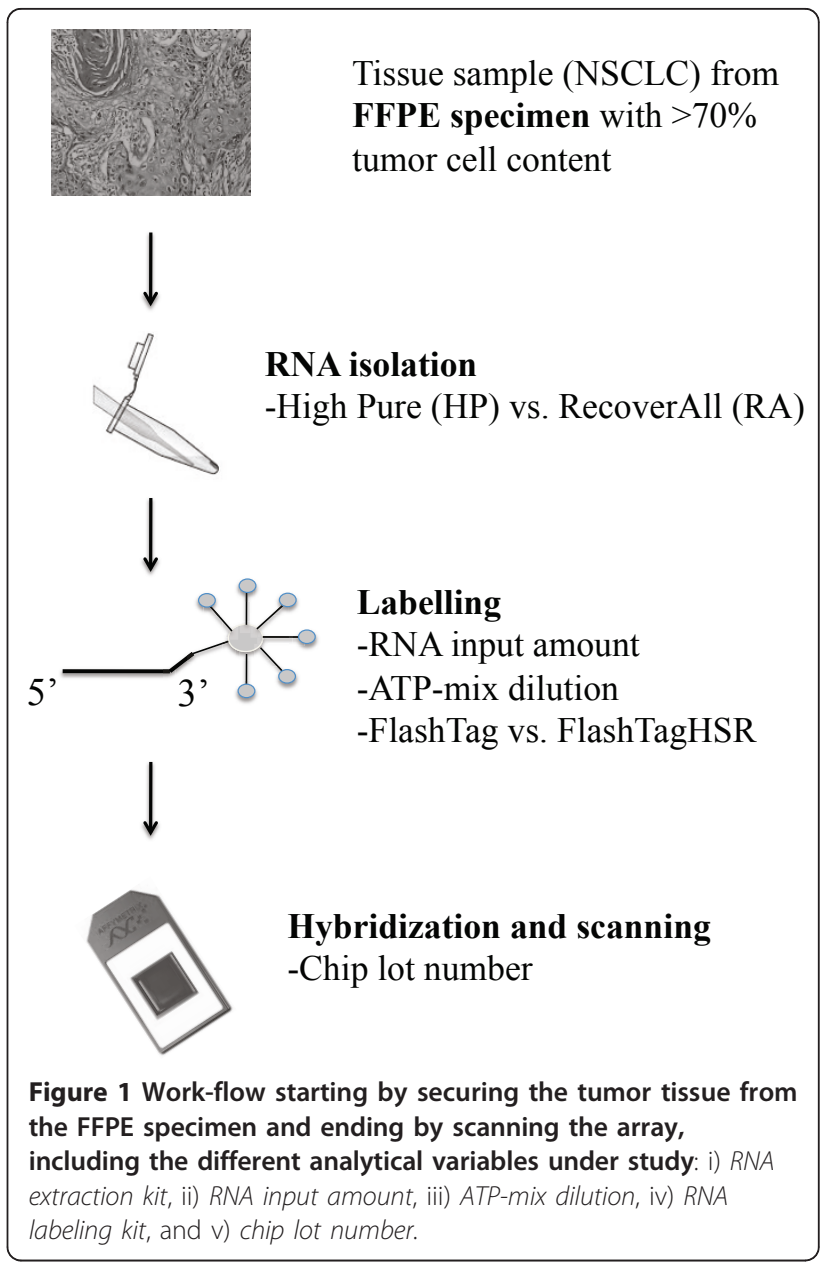

reactions. In addition, RNA was extracted twice from the same specimens in a cohort of more than 60 NSCLC patients in a direct comparison of the two assays. Thus, 139 RNA extractions and 166 hybridizations were performed from a total of 75 NSCLC specimens. To qualify the impact of any variation in the assay specific analytical conditions, principal component analysis was performed. In addition, prognosticator calls (i.e. "recurrence" or "no recurrence") was examined after varying the analytical conditions for selected samples.

\section{Results}

\section{RNA input amount}

A linear regression model showed that the amount of purified small RNA used for hybridization significantly affected mean signal intensity; the number of detected probes; and the number of detected probe sets $\left(b_{\text {signal }}=\right.$ $0.03 \pm 0.01, \mathrm{t}=2.6, \mathrm{p}<0.05, \mathrm{R}^{2}=0.58 ; b_{\text {probes }}=3.64 \pm$ $0.60, \mathrm{t}=6.0, \mathrm{p}<0.01, \mathrm{R}^{2}=0.88 ; b_{\text {probe sets }}=0.94 \pm 0.12$, $\mathrm{t}=7.6, \mathrm{p}<0.001, \mathrm{R}^{2}=0.88$; figure 2,3 and 4$)$. The amount of total RNA used for hybridization also affected the number of detected probes $\left(\operatorname{mean}_{100 \mathrm{ng}}=\right.$ 


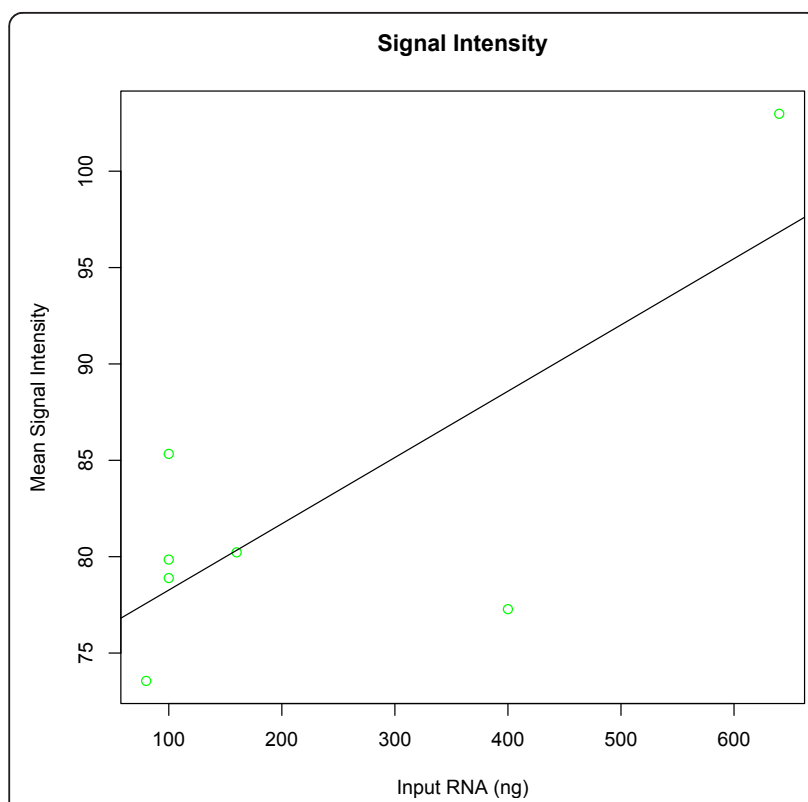

Figure 2 Mean signal intensity using varying input amounts (ng) of small RNA from an NSCLC T2 tumor that was preserved in RNAlater within 2 hours of surgery.

3674 vs. mean $_{600 ~ n g}=4627, \mathrm{t}=-2.04, \mathrm{df}=18, \mathrm{p}=0.05$; figure 5) and the number of detected probe sets $\left(\right.$ mean $_{100 \mathrm{ng}}=803$ vs. $\operatorname{mean}_{600 \mathrm{ng}}=1134, \mathrm{t}=-2.41, \mathrm{df}=$ $18, \mathrm{p}<0.05$; figure 6$)$. Self-self correlations in probe signal intensities between arrays hybridized to different amounts of the same RNA preparation varied across

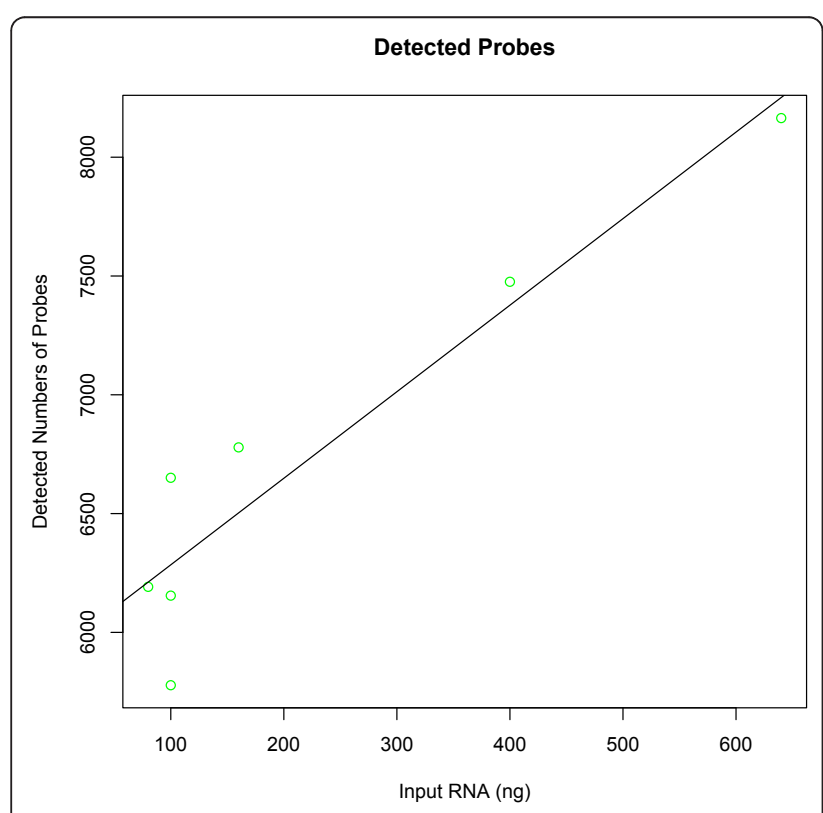

Figure 3 Number of detected probes using varying input amounts (ng) of small RNA from an NSCLC T2 tumor that was preserved in RNAlater within 2 hours of surgery.

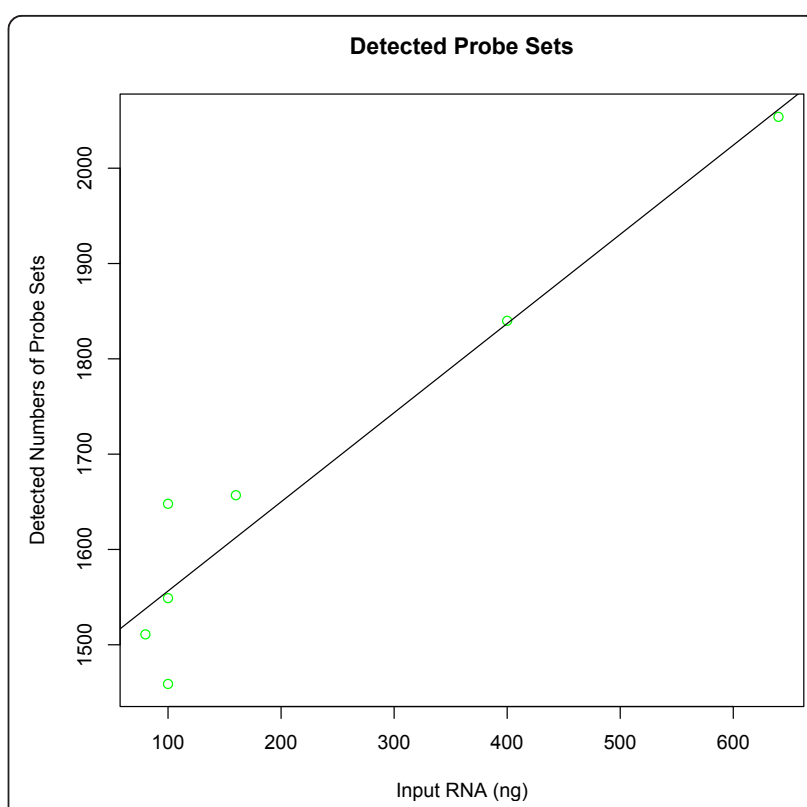

Figure 4 Number of detected probe sets using varying input amounts (ng) of small RNA from an NSCLC T2 tumor that was preserved in RNAlater within 2 hours of surgery.

different combinations of RNA input amount (table 1). In addition, a linear regression analysis revealed that self-self correlations in probe signal intensities decreased when ratios in RNA input amounts between pairs increased, considering all pair wise combinations $\left(b_{D e v R-}\right.$ NAinput $=-0.0042 \pm 0.0004, \mathrm{t}=-10.0, \mathrm{p}<0.001, \mathrm{R}^{2}=$ 0.95 ; figure 7 ).

\section{ATP-mix dilution}

The effect of ATP-mix dilution was not significant in a linear regression model (results not shown), when analyzing six hybridizations with RNA from two NSCLC specimens, each labeled using three different ATP-mix dilutions. Thus, mean signal intensity, background

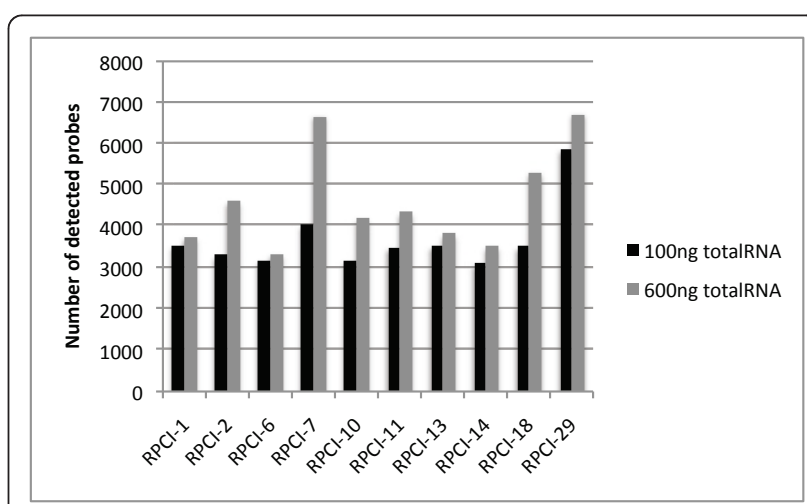

Figure 5 Number of detected probes in hybridizations where tumor samples were labeled using either $100 \mathrm{ng}$ or $600 \mathrm{ng}$ total RNA. 


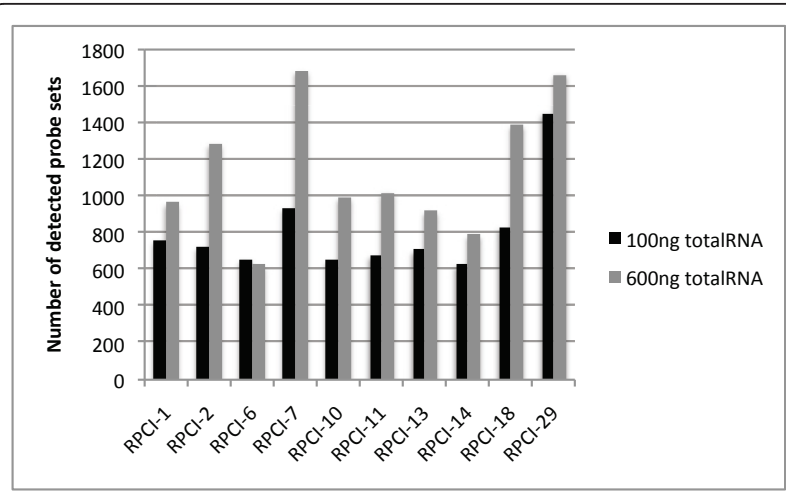

Figure 6 Number of detected probe sets in hybridizations where tumor samples were labeled using either $100 \mathrm{ng}$ or 600 ng total RNA.

intensity, the numbers of detected probes, and the numbers of detected probe sets were stable across the tested range (table 2). Self-self correlations coefficients in probe signal intensities between arrays with RNA labeled at different ATP-mix dilutions were invariant across the tested range (table 3). Thus, there were no association between self-self correlations and the ratio of ATP-mix dilutions among arrays hybridized to RNA labeled at different ATP-mix dilutions, considering all pair wise combinations (results not shown).

\section{Different chip lot numbers}

Hybridizations (in triplicates) with labeled RNA from a single T2 NSCLC tumor revealed that signal intensity and the number of probes and probe sets were not significantly different across different lot numbers (results not shown). In addition, the observed self-self correlation coefficient across probe signal intensities within and between lots did not vary (table 4). In particular, the self-self correlation coefficient across probe signal intensities within one lot of arrays ( $\mathrm{cc}=0.973$ ) was similar to the estimated average correlation between two different lots of arrays $(\mathrm{cc}=0.965 ; 95 \%$ C.I. $=0.92-1.01)$.

\section{Comparisons of two different RNA extraction kits}

Mean intensity \pm se $\left(\mathrm{x}_{\text {RecoverAll }}=247.7 \pm 26.9\right.$ vs. $\mathrm{x}_{\text {High }}$ Pure $=190.1 \pm 8.2$ ), the number of detected probes \pm se

Table 1 Correlations in signal intensities across probes from different arrays that were hybridized to four different amounts of RNA (ATP-mix dilution, 1:50) from a single preparation of a T2 NSCLC tumor.

\begin{tabular}{lcccc}
\hline RNA amount & $\mathbf{8 0} \mathbf{n g}$ & $\mathbf{1 6 0} \mathbf{n g}$ & $\mathbf{4 0 0} \mathbf{n g}$ & $\mathbf{6 4 0} \mathbf{n g}$ \\
\hline $80 \mathrm{ng}$ & - & 0.976 & 0.964 & 0.953 \\
$160 \mathrm{ng}$ & - & - & 0.974 & 0.968 \\
$400 \mathrm{ng}$ & - & - & - & 0.983 \\
$640 \mathrm{ng}$ & - & - & - & - \\
\hline
\end{tabular}

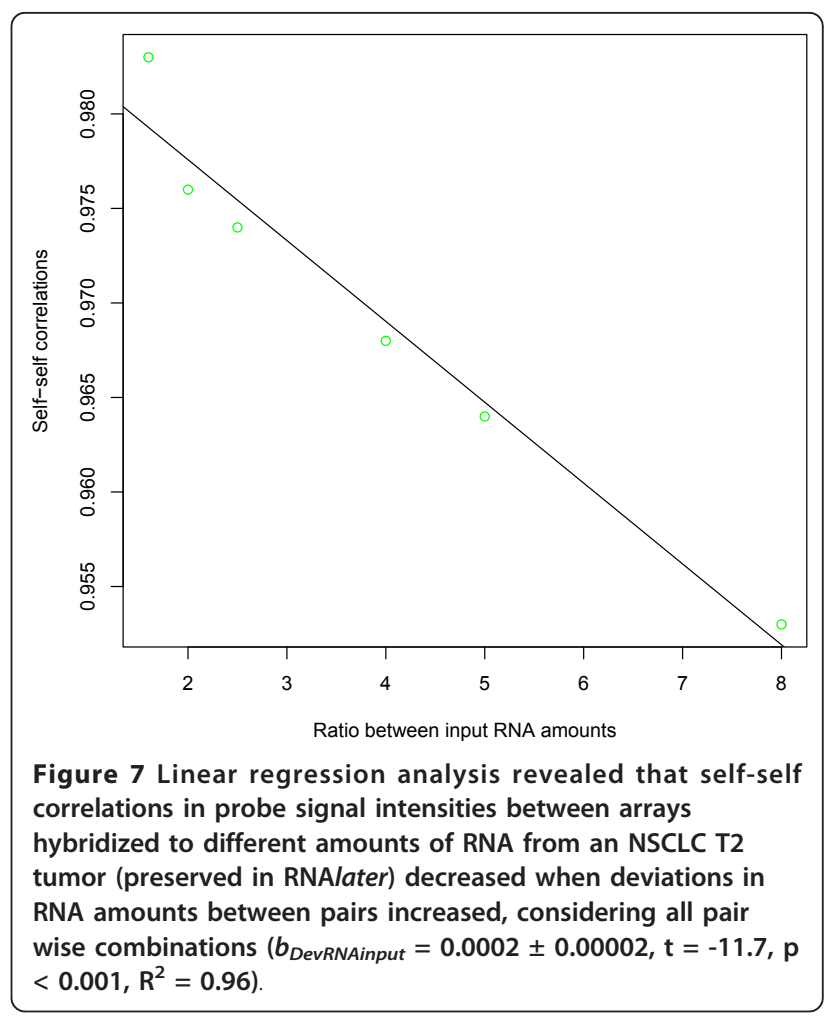

$\left(\mathrm{x}_{\text {RecoverAll }}=9407.8 \pm 98.0\right.$ vs. $\mathrm{x}_{\text {HighPure }}=7733.5 \pm$ 671.1) and the number of detected probe sets \pm se $\left(\mathrm{x}_{\mathrm{Re}}\right.$ coverAll $=2328.8 \pm 27.9$ vs. $\left.x_{\text {HighPure }}=2088.5 \pm 150.0\right)$ in hybridizations with total RNA extracted using the $R A$ kit all exceeded that for the HP kit (figure 8 and 9), although this was significant only for the numbers of detected probes (ANOVA; $\mathrm{F}_{1,6}=6.09, \mathrm{P}<0.05$ ). Background intensity was not significantly different between the kits $\left(\mathrm{x}_{\text {RecoverAll }}=56.3 \pm 2.5\right.$ vs. $\mathrm{x}_{\text {HighPure }}=51.7 \pm$ 2.0; figure 8). PCA, considering the expression of all human ncRNAs, as well as that of a specific miRNA signature for prognostication, demonstrated that a major proportion of the variance could be assigned to the two RNA extraction methods (i.e. between-kit variance) as revealed by the first principal component ( $\mathrm{PC} 1$; figure 10 and 11).

Table 2 Mean( \pm SEM) signal intensity, background intensity, number of detected probes and number of detected probe sets in hybridizations using 600 ng RNA from two NSCLC specimens (duplicates) each labeled using three different ATP-mix dilutions (1:50; 1:150 and 1:500).

\begin{tabular}{lccc}
\hline ATP-mix dilution & $\mathbf{1 : 5 0}$ & $\mathbf{1 : 1 5 0}$ & $\mathbf{1 : 5 0 0}$ \\
\hline Mean Intensity & $349 \pm 27$ & $339 \pm 19$ & $351 \pm 9$ \\
Mean Background Intensity & $89.3 \pm 0.5$ & $97.6 \pm 4.6$ & $92.3 \pm 3.7$ \\
Number of Detected Probes & $9762 \pm 213$ & $9378 \pm 435$ & $9585 \pm 139$ \\
Number of Detected Probe Sets & $2432 \pm 28$ & $2382 \pm 101$ & $2371 \pm 12$ \\
\hline
\end{tabular}


Table 3 Self-self correlations ( \pm SD) in signal intensities across probes in six hybridizations using 600 ng RNA from two NSCLC specimens with each specimen labeled with three different ATP-mix dilutions (1:50; 1:150 and 1:500).

\begin{tabular}{lccc}
\hline ATP-mix dilution & $\mathbf{1 : 5 0}$ & $\mathbf{1 : 1 5 0}$ & $\mathbf{1 : 5 0 0}$ \\
\hline $1: 50$ & - & $0.990 \pm 0.001$ & $0.990 \pm 0.0$ \\
$1: 150$ & - & - & $0.989 \pm 0.001$ \\
$1: 500$ & - & - & - \\
\hline
\end{tabular}

Comparisons of two different RNA labeling kits For hybridizations with RNA labeled using the FlashTag Biotin HSR labeling kit; mean intensity ( $\mathrm{x} \pm$ se FlashTag $H S R=215.1 \pm 18.1$ vs. $\mathrm{x} \pm$ se FlashTag $=68.3 \pm 2.9$; ANOVA; $\left.\mathrm{F}_{1,6}=64.4, \mathrm{P}<0.001\right)$, the numbers of detected probes $(\mathrm{x} \pm$ se FlashTag HSR $=8153 \pm 302$ vs. $\mathrm{x} \pm$ se $_{\text {FlashTag }}=6079 \pm 323 ;$ ANOVA; $\left.\mathrm{F}_{1,6}=21.9, \mathrm{P}<0.01\right)$ and the numbers of detected probe sets $(\mathrm{x} \pm$ se FlashTag $H S R=2139 \pm 87$ vs. $\mathrm{x} \pm$ se FlashTag $=1527 \pm 61$; ANOVA; $\mathrm{F}_{1,6}=33.5, \mathrm{P}<0.01$ ), all exceeded those in hybridizations with RNA labeled using the FlashTag Biotin labeling kit (figure 12 and 13). Background intensity was significantly different between the kits $(\mathrm{x} \pm$ se FlashTag HSR $=77.6 \pm 8.0$ vs. $\mathrm{x} \pm$ se FlashTag $=34.8 \pm 0.9$; ANOVA; $\left.\mathrm{F}_{1,6}=28.1, \mathrm{P}<0.01\right)$. A major proportion of the variance could be assigned to the different labeling methods (between-kit variance) as revealed by $\mathrm{PC} 1$ in the PCA (figure 14 and 15). PCA also revealed that the variance for samples labeled with the old labeling methods was very small (compressed).

\section{Assay I and II for prognostication in stage I NSCLC samples}

By performing 1000 Monte Carlo simulations we obtained a prognostic accuracy of $60.0 \%$ (95\% C.I.: $59.5 \%-60.5 \%$ ) for assay I and $62.6 \%$ (95\% C.I.: $61.9 \%$ $63.2 \%)$ for assay II ( $p=9.82 \mathrm{e}-10$ for the hypothesis that the accuracy is similar for the two assays). Nested LOOCV that optimized the number of selected noncoding RNAs in a separate loop resulted in an LOOCV accuracy of $63 \%$ for assay I and 73\% for assay II. A multivariate analysis examined for the effects of the miRNA chip based prognosis (i.e. "recurrence" or "no

Table 4 Correlations in signal intensities across probes from two different lots of arrays that were hybridized (in triplicates) to $100 \mathrm{ng}$ of labeled RNA (ATP-mix dilution 1:50) from of a single RNA preparation of a T2 NSCLC tumor.

\begin{tabular}{llll}
\hline Array & Chip 1, Lot “A" & Chip 2, Lot “A” & Chip 3, Lot “B” \\
\hline Chip 1, Lot "A" & - & 0.973 & 0.968 \\
Chip 2, Lot "A" & - & - & 0.961 \\
Chip 3, Lot "B" & - & - & - \\
\hline
\end{tabular}

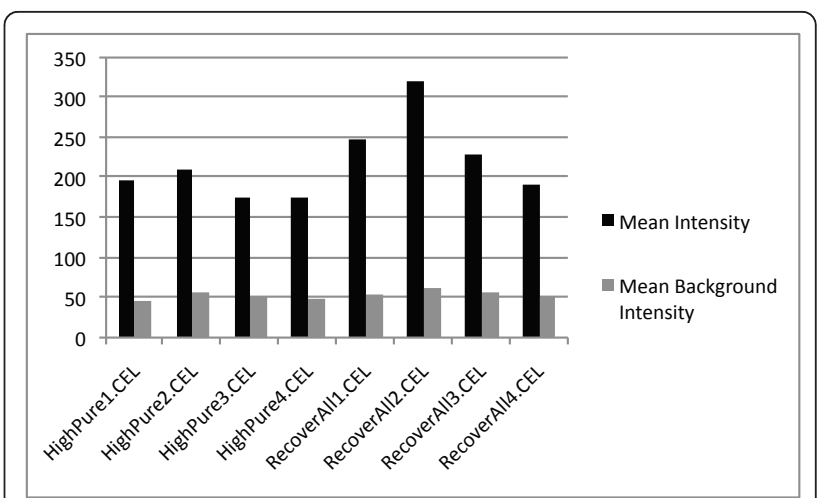

Figure 8 Mean signal and background intensities in hybridizations using RNA prepared from four tumor samples using both the HighPure and RecoverAll RNA extraction kits for FFPE studies.

recurrence"), age, smoking status, stage (Ia or Ib) and histology (squamous or adeno) on recurrence after surgery. Only the miRNA based prognosticator was significant $\left(\mathrm{P}_{\text {miRNA Prognosis }}=0.009 ; \mathrm{P}_{\text {Age }}=0.656, \mathrm{P}_{\text {Smoking }}=\right.$ $0.146, \mathrm{P}_{\text {Stage }}=0.921, \mathrm{P}_{\text {Histology }}=0.732$ ). Figure 16 shows the predictions against a Kaplan-Meier time-to recurrence plot (LOOCV accuracy of $73 \%, \mathrm{p}<0.001$ ). The two miRNA lists obtained did not overlap and the list obtained from one assay could not predict the other assay.

Impact of the analytical conditions on the robustness of the prognosticator

Prognosticator calls (i.e. "recurrence" or "no recurrence") were consistent independent of the RNA amount, ATP-mix dilution, chip lot number and RNA extraction method being used. In contrast, the calls were not robust to changes in labeling method (table 5).

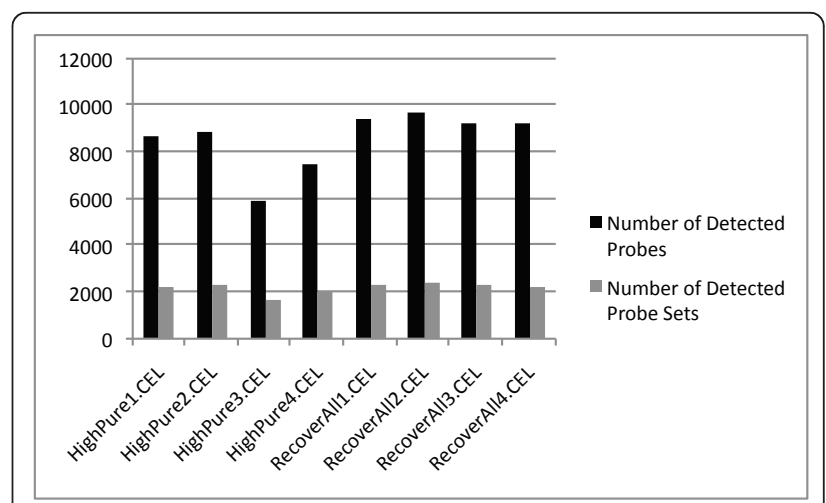

Figure 9 Number of detected probes and probe sets in hybridizations using RNA prepared from four tumor samples using both the HighPure and RecoverAll RNA extraction kits for FFPE studies 


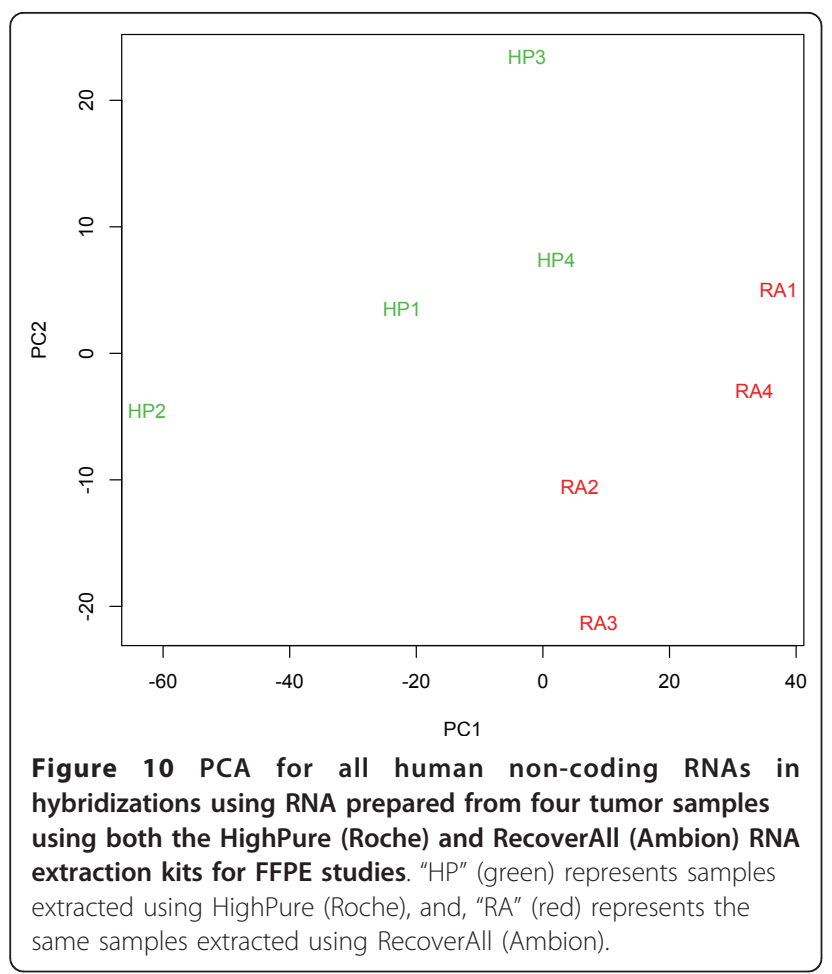

\section{Discussion}

Validation of a microarray based laboratory assay poses two technical challenges; first, ensuring that data are aquired with the best laboratory proficiency; and second,

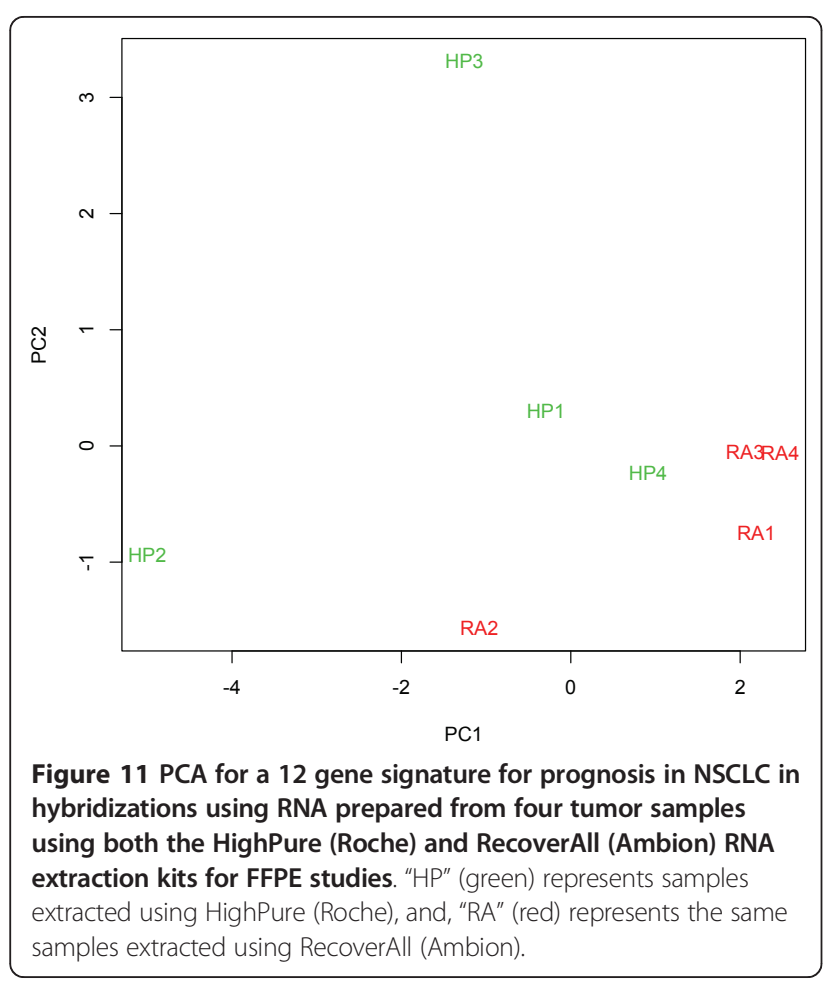

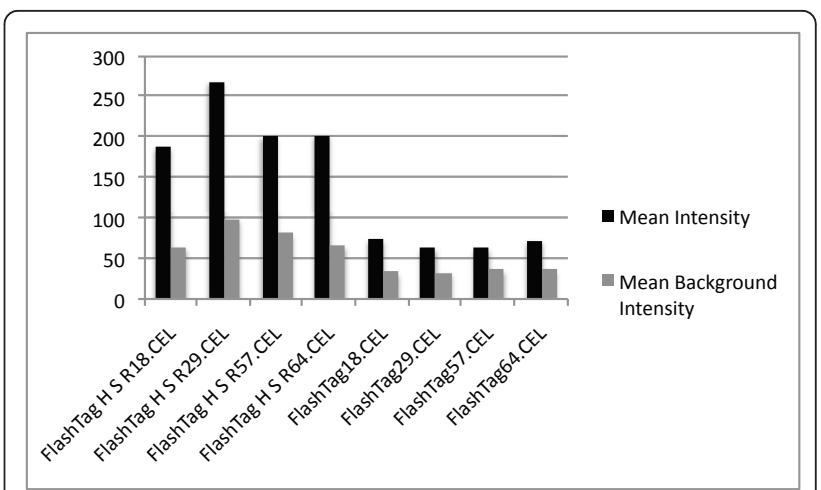

Figure 12 Mean signal and background intensities in hybridizations using RNA from four tumor samples labeled with the FlashTag Biotin- and FlashTag Biotin HSR labeling kits.

that data are analyzed appropriately. In order for a chip based prognostic assay to be practically usefull and accurate for prognostication in NSCLC, concern must be adressed towards the concordance of expression measurements and the impact of variation across analytical conditions. Here we assessed the impact of variation in several analytical conditions including varying RNA input amount, ATP-mix dilution, chip lot numbers, RNA extraction- and RNA labeling kit.

\section{RNA input amount}

Increasing the input RNA amounts led to an increase in mean signal intensity and the number of detected probes and probe sets (figure 2, 3, 4 and 5). Since no amplification step is applied in either of the labeling kits under test, this finding is expected. Also, as deviations in RNA input amounts affected self-self correlations, concern should be addressed to avoid large variations in the amount of input RNA in similar miRNA based laboratory assays (figure 7).

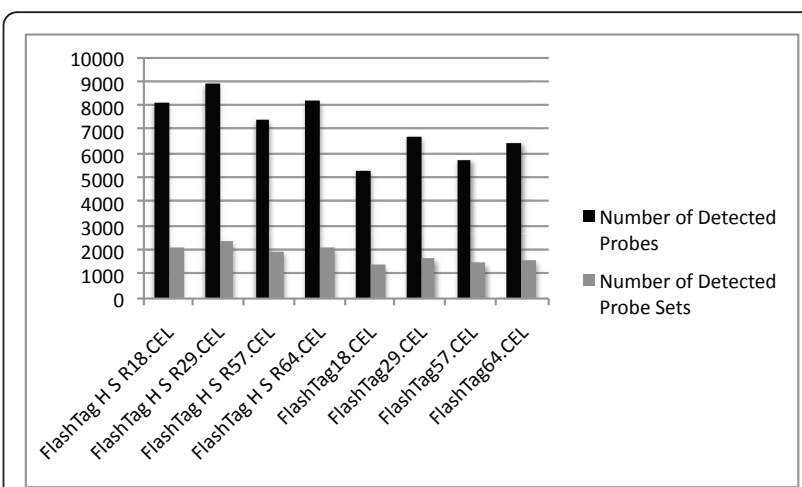

Figure 13 Number of detected probes and probe sets in hybridizations using RNA from four tumor samples labeled with the FlashTag Biotin- and FlashTag Biotin HSR labeling kits. 


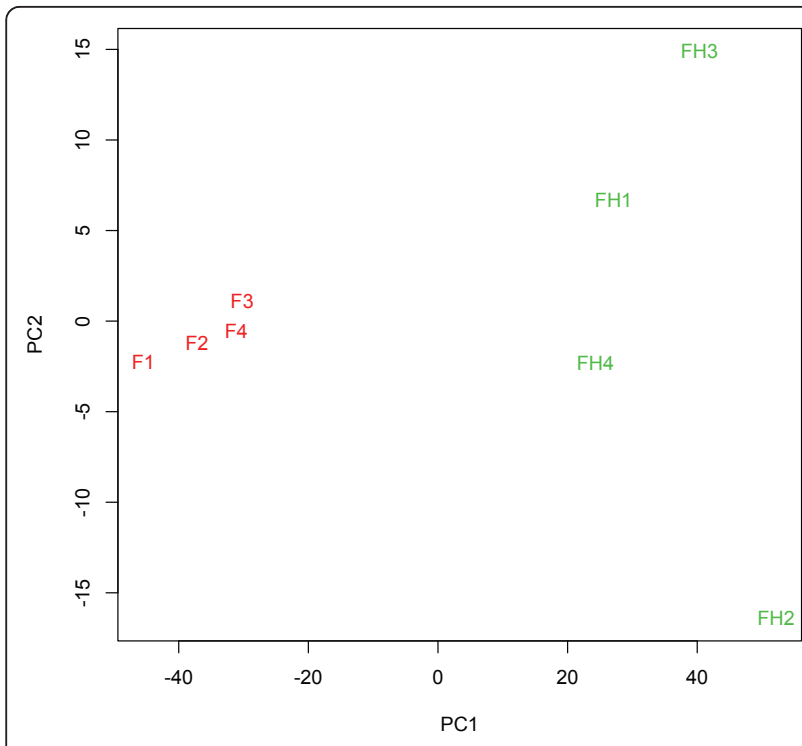

Figure 14 PCA for all human non-coding RNAs in hybridizations using RNA from four tumor samples labeled with both the FlashTag Biotin- and FlashTag Biotin HSR labeling kits. $F$ (red) represents samples labeled with the FlashTag Biotin kit, and, FH (green) represents the same samples labeled with the FlashTag Biotin HSR labeling kit.

\section{ATP-mix dilution}

When 600 ng RNA (obtained with the RA kit) was used as input in labeling reactions, ATP-mix dilutions did not significantly affect mean signal intensity and the

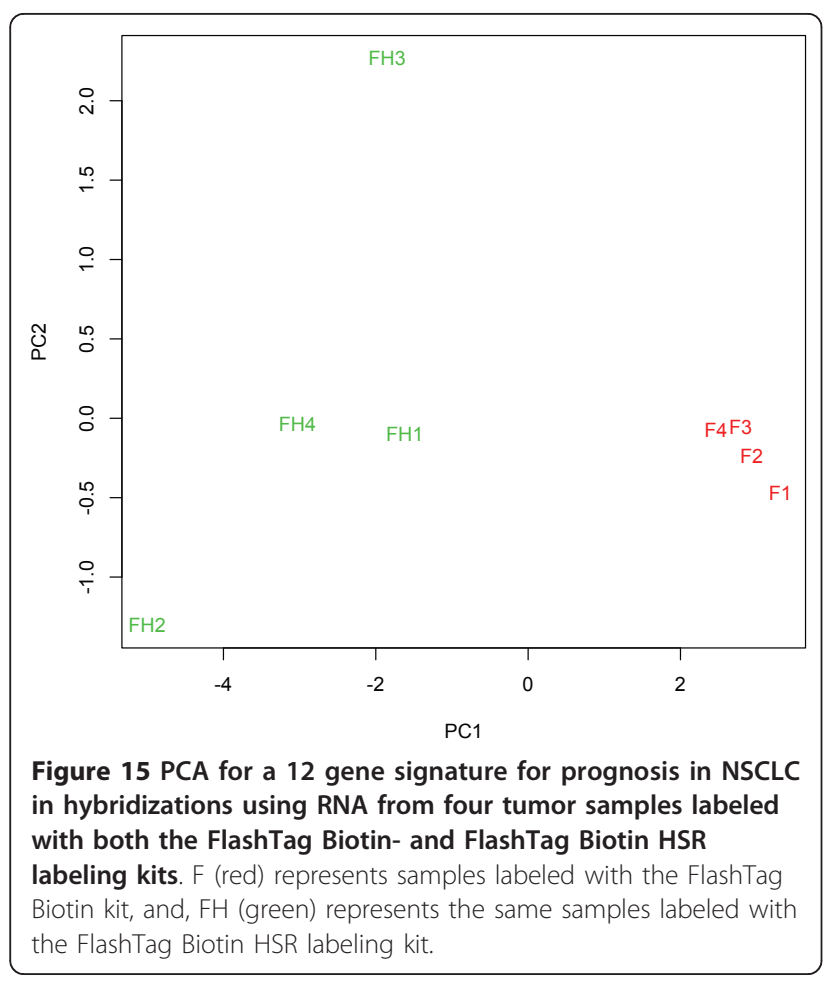

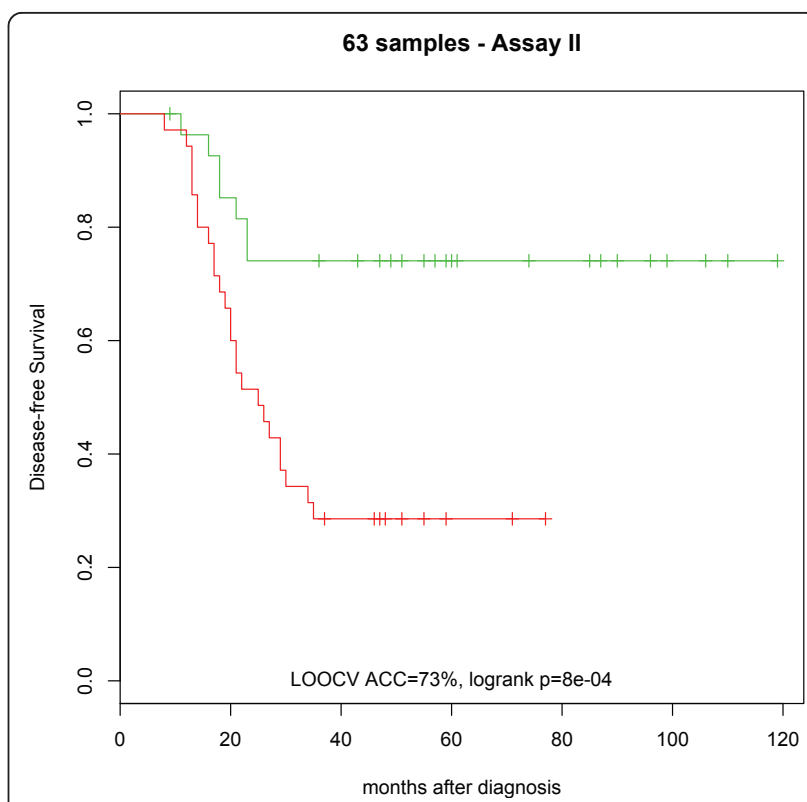

Figure 16 Kaplan-Meier plots of disease-free survival predictions $(n=63)$ in a leave-one-out cross-validation analysis (using the SVM-based classifier). Cases predicted to have recurrence are plotted separately (red) from those predicted to be recurrence-free (green).

number of detected probes and probe sets. Self-self correlations in probe signal intensities between arrays were also not affected by changing ATP-mix dilutions (table 3). Thus experimental variation in ATP-mix dilutions appear to have no impact.

\section{Different chip lot numbers}

Correlations in signal intensities (table 4) were not affected by different lot numbers of arrays. This result was anticipated in part due to the In Vitro Diagnostics status of the Affymetrix gene array scanner being used here. In addition, Wen et al. [19] have demonstrated that even for arrays that were expired by several years (and of different lot numbers) the percentage of overlap between lists of differentially expressed genes from the expired and unexpired microarrays was $96.99 \%$. In addition, microarray data generated using the expired microarrays were highly concordant with microarray and TaqMan $^{\circledR}$ data generated by the MAQC project several years before [19].

\section{Comparison of the HighPure and RecoverAll purification kits for FFPE studies}

Mean intensity and the number of detected probes and probe sets, in RNA preparations from the $R A$ extraction kit, all exceed that detected in RNA preparations obtained from the HP extraction kit. This is consistent with previous findings [14], showing that miRNA 
Table 5 Prognosticator calls ( 0 ="no recurrence" or $1=$ "recurrence") were examined for varying RNA input amounts (a single T2 NSCLC specimen), ATP-mix dilutions (two NSCLC specimens), chip lot numbers (a single T2 NSCLC specimen), RNA extraction kits (four NSCLC specimens; HP = HighPure, Roche \&RA = RecoverAll, Ambion) and RNA labeling kits (four NSCLC specimens; $F$ = Flashtaq and FH = Flashtaq HSR, Genisphere) for selected samples using the prognostic profile of assay II.

\begin{tabular}{|c|c|c|c|c|c|c|c|c|}
\hline RNA amount & Call & Recurrence & Chip lot & Call & Recurrence & Labeling kit & Call & Recurrence \\
\hline 80 ng & 1 & - & Lot $x$ & 1 & - & $\mathrm{RPCl}-18-\mathrm{F1}$ & 1 & No \\
\hline $100 \mathrm{ng}$ & 1 & - & Lot $x$ & 1 & - & $\mathrm{RPCl}-29-F 2$ & 1 & Yes \\
\hline $100 \mathrm{ng}$ & 1 & - & Lot $y$ & 1 & - & $\mathrm{RPCl}-57-F 3$ & 1 & No \\
\hline $100 \mathrm{ng}$ & 1 & - & & & & $\mathrm{RPCl}-64-F 4$ & 1 & No \\
\hline $160 \mathrm{ng}$ & 1 & - & & & & & & \\
\hline $400 \mathrm{ng}$ & 1 & - & RNA extraction kit & & & $\mathrm{RPCl}-18-\mathrm{FH} 1$ & 0 & No \\
\hline \multirow[t]{2}{*}{$640 \mathrm{ng}$} & 1 & - & & & & $\mathrm{RPCl}-29-\mathrm{FH} 2$ & 0 & Yes \\
\hline & & & KH882A9 - HP & 0 & - & $\mathrm{RPCl}-57-\mathrm{FH} 3$ & 0 & No \\
\hline \multirow[t]{2}{*}{$\underline{A T P-m i x}$ dilution } & & & $\mathrm{KH} 22716 \mathrm{D} 3-\mathrm{HP}$ & 0 & - & $\mathrm{RPCl}-64-\mathrm{FH} 4$ & 0 & No \\
\hline & & & $\mathrm{KH} 24218 \mathrm{~B} 4-\mathrm{HP}$ & 0 & - & & & \\
\hline A-504; 1:50 & 0 & - & KH24935B5 - HP & 0 & - & & & \\
\hline A-504; 1:150 & 0 & - & & & & & & \\
\hline A-504; 1:500 & 0 & - & $\mathrm{KH} 882 \mathrm{~A} 9-\mathrm{RA}$ & 0 & - & & & \\
\hline B-652; 1:50 & 0 & No & $\mathrm{KH} 22716 \mathrm{D} 3-\mathrm{RA}$ & 0 & - & & & \\
\hline B-652; 1:150 & 0 & No & $\mathrm{KH} 24218 \mathrm{~B} 4-\mathrm{RA}$ & 0 & - & & & \\
\hline B-652; 1:500 & 0 & No & $\mathrm{KH} 24935 \mathrm{~B} 5-\mathrm{RA}$ & 0 & - & & & \\
\hline
\end{tabular}

Data for recurrence was available only for the test of labeling kit and for one sample used to test ATP-mix dilution.

expression signals may be reduced when RNA is extracted using the HighPure miRNA isolation kit (Roche). Doleshal et al. [14], compared five different miRNA extraction kits and concluded that three of the kits showed two- to three-fold lower total RNA yield, and five- to 20-fold lower miRNA qRT-PCR signals at equal RNA mass input compared to alternative extraction kits, including RecoverAll (Ambion). PCA for all human non-coding RNAs revealed substantial variation between the two extraction kits. Thus, the results of the PCA indicate that a particular tumor sample is more distantly separated from itself when RNA is extracted with a different kit, as compared with tumor samples from different patients when RNA is extracted with the same kit. As a consequence, the two RNA extraction procedures are not interchangeable within either an experiment, or across different experiments that are performed for validation purposes.

\section{Comparison of the FlashTag Biotin and FlashTag Biotin HSR labeling kits}

Mean intensity and the number of detected probes and probe sets, in RNA preparations labeled with the FlashTag Biotin HSR labeling kit, all exceed those in RNA preparations labeled with the original FlashTag Biotin labeling kit. PCA for all human non-coding RNAs revealed substantial variation between the two labeling kits. The results of the PCA indicate that a particular tumor sample is more distantly separated from itself when RNA is labeled with a different kit, as compared to tumor RNA samples from different patients labeled with the same kit. Within-kit variance for the FlashTag Biotin labeling kit was very small compared to the FlashTag Biotin HSR labeling kit. The small variance for the FlashTag Biotin labeling kit may be a consequence of a compressed mean (and variance) in signal intensity (figure 12), in addition to a reduced detection of probes and probes sets with this kit compared to the FlashTag Biotin HSR labeling kit (figure 13), when the same samples were processed. As a consequence, the two RNA labeling procedures are not interchangeable either within an experiment, or across different experiments that are performed for validation purposes.

\section{Comparisons of Assays I \& II}

By comparing assay I and assay II using a profile of fixed size (i.e. 30 non-coding RNAs) for each assay, and performing 1000 Monte Carlo simulations, a significantly better performance of assay II (62.6\%) was observed as compared to assay I (60\%). The accuracy of the final profiles (after performing nested LOOCV) for assay I and assay II were $63 \%$ and $73 \%$ respectively, again pointing to a better performance of assay II. A Kaplan-Meier time-to recurrence plot using data from assay II demonstrated a clear and significant separation of the predicted "recurrence" and "no recurrence" groups (LOOCV accuracy of 73\%, p < 0.001; figure 16). The miRNA list obtained on one assay, however, could 
not predict NSCLC samples profiled using the other assay adding to the importance of extraction and labeling kits on performance of miRNA based classifiers. The observed accuracy of assay II was lower compared to an assay developed using the Exiqon platform that demonstrated an accuracy of $83 \%$, in spite of the same patient samples being used in both studies [6]. This may in part be due to the larger number of samples being assayed in the study using the Exiqon platform [6]. Even though the profiles of the two platforms are not identical, the assay in Patnaik et al. [6] and assay II maintained a high accuracy, which is consistent with the MAQC studies that demonstrated that data quality from single- and two color platforms was essentially equivalent [20].

\section{Impact of the analytical conditions on the robustness of the prognosticator}

The prognosticator calls (i.e. "recurrence" or "no recurrence") for selected samples under varying analytical conditions (table 5) were consistently independent of the RNA input amount, ATP-mix dilution, chip lot number and RNA extraction method being used. In contrast, the calls were not robust to changes in labeling method. Overall, the results support that labeling method (figure 14 and 15) and possibly also RNA extraction method, due to large variation in PCA (figure 10 and 11), must be held constant in order to provide for consistent results. Since both of these variables differed between assay I and assay II, changing each of them, or both, in general may prevent a miRNA list obtained in one assay from being able to predict NSCLC samples profiled using another assay, as we found in this study.

\section{Conclusions}

In this study, we demonstrate that some analytic variables are important for the variation in assay performance while others are not. Thus, careful optimization that address all analytical steps and variables can facilitate the introduction of microRNA arrays for prediction of relapse in stage I non-small cell lung cancer (NSCLC). In result, stratification of patients with stage I disease can be improved by prediction of relapse after surgery, potentially allowing to direct intensive surveillance and/or adjuvant therapy toward patients at high risk of relapse (figure 16).

\section{Methods}

\section{Patients and Tissue Specimens}

Patient tumor samples were collected retrospectively from Roswell Park Cancer Institute (RPCI), Buffalo, NY and from Aarhus and Odense University Hospitals in Denmark. The use of all included samples in this study was approved by the institutional review board at Roswell Park Cancer Institute, and, in Denmark, by Den
Videnskabsetiske Komité. The study was conducted in accordance with the Helsinki declaration. In total 75 NSCLC specimens were included in the study. These comprised 68 stage I NSCLC from a US cohort collected and treated at RPCI [6] and seven NSCLC specimens collected in Denmark. Clinical data were obtained only for the US cohort, from the tumor registry at RPCI and through chart reviews [6]. Approximately half of the patients from the US cohort were known to have had a recurrence. The recurrence-free cases were followed for at least 32 months, with approximately half of them followed for at least 5 years [6]. For the US specimens and for two Danish specimens, tissue cores were sampled from FFPE tissue blocks from areas with $>70 \%$ tumor cell content (as verified by HE-stain), and subsequently cores were re-embedded in paraffin. For the remaining four FFPE specimens, tissues sections $(20 \mu \mathrm{m}$ thick) were obtained for the comparison of the two RNA extraction kits. One NSCLC specimen was collected within two hours of surgery and was preserved in RNAlater (Ambion, Inc 2130 Woodward St. Austin, TX) with approval by Den Videnskabsetiske Komité in Denmark and with informed consent obtained from the patient.

\section{RNA extraction}

In a PubMed http://www.ncbi.nlm.nih.gov/pubmed search using the search terms "miRNA" AND "Cancer" AND "FFPE", 33 publications were retrieved covering the period from 2009 to 2011 . Of these, 16 publications described the use of global miRNA profiling, and in over half of these (i.e. in 9 studies), RNA was extracted using the RecoverAll kit (Ambion). In the present study we compared two different RNA extraction methods. In addition to the widely used RecoverAll kit ("RA Kit", Ambion), we included the High Pure miRNA Isolation Kit ("HP Kit", Roche Applied Science, 68298 Mannheim, Germany). For the HP Kit, RNA was extracted from deparaffinized and proteinase K-treated FFPE core tissues (20-40 mg) or sections according to the manufacturer's instructions. In approximately one-third of the cases, RNA preparations were of poor quality. Consequently, RNA was extracted again from FFPE tissue. For the RA Kit, RNA was extracted from deparaffinized and protease-treated FFPE core tissues (20-40 mg) or sections with on column DNAse digestion according to the manufacturer's instructions. RNA concentration and quality was assessed by absorbance spectrometry and electrophoresis using the NanoDrop (Thermo Fisher Scientific, Wilmington, DE) and Bioanalyzer 2100 (Agilent Technologies) instruments.

\section{Labeling of RNA}

Two different RNA labeling methods were compared in this study; the FlashTag ${ }^{\mathrm{TM}}$ Biotin RNA Labeling Kit 
(Genisphere, PA), and the new HSR version of the same kit were used according to the manufacturer's instructions unless otherwise stated. Poly (A)-tailing: 100-800 ng RNA including the small RNA species was used as starting material for the polyA-tailing reaction with different ATP-mix dilutions (from 1:10-1:500). Poly (A)tailing was performed at $37^{\circ} \mathrm{C}$ for 15 minutes (GeneAmp PCR System 9700, Applied Biosystems, Foster City, CA). Ligation: Using the entire reaction product from the poly (A) tailing reaction, a biotin-labeled $3 \mathrm{DNA}^{\circledR}$ dendrimer was ligated to the poly (A) tails using a T4 DNA Ligase and incubated at $25^{\circ} \mathrm{C}$ for 30 minutes (GeneAmp PCR System 9700, Applied Biosystems ${ }^{\circledR}$ ) following the manufacturer's instructions.

\section{Hybridization}

Of the 16 studies from the PubMed http://www.ncbi. nlm.nih.gov/pubmed search describing global miRNA profiling, 12 studies used six different commercially available platforms and the remaining four studies used different custom platforms. Between 365 and 847 human miRNAs were profiled using from $20 \mathrm{ng}$ to $5 \mathrm{ug}$ totalRNA as input. In the present study we used the platform with the broadest coverage, i.e. the Afymetrix GeneChip ${ }^{\circledR}$ miRNA Array that interrogates 847 human miRNAs and about an equal number of small non-coding RNAs. Hybridization washing and staining were performed using the Affymetrix GeneChip Hybridization, Wash and Stain Kit (Affymetrix, CA). Briefly, the hybridization cocktail containing the biotin labeled RNA was heated to $99^{\circ} \mathrm{C}$ for 5 minutes and then to $45^{\circ} \mathrm{C}$ for 5 minutes (GeneAmp PCR System 9700, Applied Biosystems ${ }^{\circledR}$ ) before loading onto the Affymetrix probe array cartridge (GeneChip ${ }^{B}$ miRNA Array). The volume of the hybridization cocktail loaded on the chip was changed from $100 \mathrm{ml}$ to $80 \mathrm{ml}$ in order to improve movement/flow of the cocktail in the hybridization chamber, ensuring a better and more even hybridization process. Thus, in effect only $80 \%$ of the labeled RNA was placed on the chip. The probe array was incubated for 17 hours at $48^{\circ} \mathrm{C}$ with constant rotation (60 r.p.m.). The probe array was incubated for $17 \mathrm{~h}$ at $48^{\circ} \mathrm{C}$ at constant rotation (60 r.p.m.). The biotin labeled RNA was stained with a streptavidin-phycoerythrin conjugate and the signals amplified using a biotinylated goat antibody against streptavidin. Finally, the samples were stained with a streptavidin-phycoerythrin conjugate.

\section{Scanning}

The probe arrays were scanned using a confocal laserscanning microscope (Affymetrix GCS3000Dx2). The readings from the quantitative scanning were analyzed using the Affymetrix Molecular Diagnostics Software (AMDS). The microarray data was deposited in the
Array Express public database http://www.ebi.ac.uk/ arrayexpress/ and has been assigned accession number E-MTAB-618 (under experiment name: Laboratory assays for prediction of relapse in stage I non-small cell lung cancer (NSCLC)).

\section{RNA input amount}

For comparisons, RNA was extracted from a sample collected under conditions where RNA degradation is expected to be minimal. Thus, a sample of a T2 NSCLC post-resection surgical specimen was collected and preserved in RNAlater (Ambion) within 2 hours of after surgery. RNA was subsequently extracted using the $H P$ Kit. The effect of varying RNA input amounts $(80,100$, 160, 400 and $640 \mathrm{ng}$ ) for hybridization was examined. In addition, RNA was prepared from ten stage I NSCLC surgical FFPE specimens using the HP Kit (100 and 600 ng) and these samples were labeled and hybridized to miRNA arrays. Signal intensities were examined on the chip using laser scanning microscopy. Background intensity ranged from 31 to 36 and was unrelated to the amount of input RNA (results not shown). Subtraction of background intensities did not affect the results (data not shown).

\section{ATP-mix dilution}

The effect of different ATP-mix dilutions (1:10; 1:50 and 1:100) was examined using 100 ng RNA extracted from a single NSCLC specimen using the HP Kit and labeled using the FlashTag ${ }^{\mathrm{TM}}$ Biotin RNA Labeling Kit (Genisphere). In addition, different ATP-mix dilutions (1:50; $1: 150$ and $1: 500)$ were examined using two preparations of $600 \mathrm{ng}$ RNA extracted from two different NSCLC FFPE specimens using the RA Kit and labeled using the FlashTag ${ }^{\mathrm{TM}}$ Biotin HSR RNA Labeling Kit (Genisphere).

\section{Different chip lot numbers}

Correlations in signal intensities were examined across two different lots of arrays that were hybridized (in triplicates) to $100 \mathrm{ng}$ of labeled RNA (FlashTagTM Biotin RNA Labeling Kit, ATP-mix dilution 1:50) from of a single RNA preparation of a T2 NSCLC tumor using the HP Kit.

\section{Comparisons of two different RNA extraction kits}

The High Pure miRNA Isolation Kit ("HP Kit ", Roche) and RecoverAll ("RA Kit", Ambion) extraction methods were compared in an RNA extraction experiment with four FFPE NSCLC specimens. From each specimen, 20 sections ( $20 \mathrm{~mm}$ thick) were cut, every other slide being used for one extraction method and the remaining slides for the other. For each extraction method, 1000 ng RNA of each specimen was polyadenylated (ATP-mix dilution 
1:50) and labeled with biotin using the FlashTag ${ }^{\mathrm{TM}}$ Biotin HSR RNA Labeling Kit (Genisphere, PA).

\section{Comparisons of two different labeling kits}

The FlashTag ${ }^{\mathrm{TM}}$ Biotin RNA Labeling Kit (Genisphere), and the new $H S R$ version of this kit were compared in an RNA labeling experiment using RNA from four NSCLC specimens from the RPCI cohort extracted using the HP Kit. For each labeling kit, 600 ng RNA from each specimen was polyadenylated (ATP-mix dilution 1:50) and labeled with biotin.

\section{Assay I and II for prognostication in stage I NSCLC}

For assay I, total RNA including small RNA was extracted from 68 stage I NSCLC specimens using the High Pure miRNA Isolation Kit (Roche) and 600 ng was labeled using the FlashTag ${ }^{\mathrm{TM}}$ Biotin RNA Labeling Kit (Genisphere). For assay II, total RNA including small RNA was extracted from 63 of the 68 stage I NSCLC specimens using RecoverAll (Ambion) and $600 \mathrm{ng}$ was labeled using the FlashTag ${ }^{\mathrm{TM}}$ Biotin HSR RNA Labeling Kit (Genisphere).

\section{Prognostic profile based on non-coding small RNA species}

We tested the performance of a SVM classifier on both assays using a Monte Carlo approach. First, two-thirds of a data set was randomly chosen and used as a training set. Second, training was done by setting the number of features (i.e. non-coding RNAs) to 30, chosen according to a highest $\mathrm{t}$ statistic, MCRestimate package [21], in a LOOCV-loop. The 30 most frequent features were used for training of the SVM classifier. Third, performance was measured on one-third of the data set left out. Finally, the above procedure was repeated 1000 times. A nested LOOCV approach was further used to identify the optimal number of non-coding RNAs in the following way: First, a test sample was held out in the outer loop (leaving N-1 samples). In the inner loop LOOCV on N-1 samples was used to determine the accuracy for a range of selected features. Here, features were first selected based on the highest $t$ statistic mentioned above. Next, selected features were used as input to the SVM classifier to classify each left out sample in turn. Subsequently, the number of features yielding the highest accuracy was used to classify the test sample that was held out in the outer loop. Ultimately, the most frequent number of features yielded the chosen prognostic profile.

\section{Impact of analytical conditions on the robustness of the prognosticator}

To qualify the impact of any variances in the analytical conditions of the assay, the calls (i.e. "recurrence" or "no recurrence") of the prognosticator were examined after varying RNA input amount, ATP-mix dilution, chip lot numbers, RNA extraction kit and RNA labeling kit for eleven selected NSCLC samples. The prognosticator was trained using either 68 (assay I) or 63 (assay II) stage I NSCLC samples using a SVM classifier and the identified prognostic profiles of each assay. Second, the trained SVM classifier was used to predict the outcome and thus examine the robustness of the prognosticator.

\section{Statistical analysis and Bioinformatics analysis}

For testing the effects of RNA amount; ATPmix dilution; extraction kit and labeling kit on signal intensity, background intensity, the numbers of detected probes and probe sets, arrays were pre-processed using Affymetrix miRNA QC Tool 1.0.33 (with workflow set to "default"). T-tests and ANOVA, assuming equal variances were performed using the $\mathrm{R}$ software package [22]. For correlation analysis, data normalization was performed using the justRMA procedure in Bioconductor [21] generating expression indexes (log with base 2) for all human features on the Affymetrix GeneChip miRNA Arrays. Principal component analysis (PCA) was performed using all human non-coding RNAs and the extracted signature for prognostication. For the prognostic profiles we used the raw miRNA data without background correction. We used perfect match probes only and summarized with average difference.

\section{Acknowledgements}

This work was supported by a grant from the Danish Agency for Science, Technology and Innovation. SY was supported by a grant from the Buswell Foundation. We are grateful to consultant MD. Karen Ege, Dept. Pathology, Odense University Hospital for her help and advice regarding the NSCLC specimens and to PhD Santosh Patnaik (Roswell Park Cancer Institute) for his constructive comments on the manuscript.

\section{Author details}

${ }^{1}$ Medical Prognosis Institute, Venlighedsvej 1, 2970 Hørsholm, Denmark. ${ }^{2}$ Department of Thoracic Surgery, Roswell Park Cancer Institute, Buffalo, New York, USA. ${ }^{3}$ Department of Oncology, Odense University Hospital, Sdr. Boulevard 29, DK-5000 Odense C, Denmark. ${ }^{4}$ Department of Cancer and Inflammation Research, Institute for Molecular Medicine (IMM), University of Southern Denmark, J. B. Winsloews Vej 25, DK-5000 Odense C, Denmark. ${ }^{5}$ Institute of Pathology, Aarhus University Hospital, Noerrebrogade 44, Bygning 18, DK-8000 Aarhus C, Denmark. 'Department of Pathology, Roswell Park Cancer Institute, Buffalo, New York, USA.

\section{Authors' contributions}

JD: Design of study, acquisition of miRNA expression data, statistical data analysis and data interpretation, drafting of the manuscript and final approval. WM: Design of study, statistical data analysis including prognostic models and interpretation, revising the manuscript and final approval. TJ: Design of study; acquisition and interpretation of miRNA expression data; revising the manuscript and final approval. MP: Collection and acquisition of data from FFPE specimens, revising the manuscript and final approval. WB: Collection and acquisition of data from FFPE specimens, revising the manuscript and final approval. AH: Acquisition of miRNA expression data, revising the manuscript and final approval. EK: Acquisition of data, revising the manuscript and final approval. SJHD: Acquisition of data from FFPE specimens, revising the manuscript and final approval. OH: Acquisition of 
data, revising the manuscript and final approval. $\mathrm{HH}$ : Collection and acquisition of data from FFPE specimens, revising the manuscript and final approval. HJD: Acquisition of data; revising the manuscript and final approval. SY Design of study; acquisition and interpretation of clinical data revising the manuscript and final approval. SK Design of study, interpretation and analysis of data including prognostic models, revising the manuscript and final approval.

\section{Competing interests}

J Dahlgaard, W. Mazin, T Jensen, A Hansen and S. Knudsen are employees at Medical Prognosis Institute, Denmark, a company that focuses on developing microarray-based technology for cancer treatment. The other authors disclosed no potential competing interest.

Received: 1 August 2011 Accepted: 19 October 2011

Published: 19 October 2011

\section{References}

1. Goldstraw P, Crowley J, Chansky K, Giroux DJ, Groome PA, Rami-Porta R, Postmus PE, Rusch V, Sobin L, International Association for the Study of Lung Cancer International Staging Committee; Participating Institutions: The IASLC Lung Cancer Staging Project: proposals for the revision of the TNM stage groupings in the forthcoming (seventh) edition of the TNM Classification of malignant tumours. J Thorac Oncol 2007, 8:706-14.

2. Pignon J-P, Tribodet H, Scagliotti GV, Douillard J-Y, Shepherd FA, Stephens RJ, Dunant A, Torri V, Rosell R, Seymour L, Spiro SG, Rolland E, Fossati R, Aubert D, Ding K, Waller D, Chevalier TL: Lung Adjuvant Cisplatin Evaluation: A Pooled Analysis by the LACE Collaborative Group. J Clin Oncol 2008, 26:3552-9.

3. Yanaihara N, Caplen N, Bowman E, Seike M, Kumamoto K, Yi M, Stephens RM, Okamoto A, Yokota J, Tanaka T, Calin GA, Liu C-G, Croce CM, Harris CC: Unique microRNA molecular profiles in lung cancer diagnosis and prognosis. Cancer Cell 2006, 9:189-98.

4. Yu SL, Chen HY, Chang GC, Chen Chih-Yi, Chen H-W, Singh S, Cheng C-L, Yu C-J, Lee Y-C, Chen H-S, Su T-J, Chiang Ching-Cheng, Li H-N, Hong Q-S, Su H-Y, Chen C-C, Chen W-J, Liu C-C, Chan W-K, Chen WJ, Li K-C, Chen JJW, Yang P-C: MicroRNA signature predicts survival and relapse in lung cancer. Cancer Cell 2008, 13:48-57.

5. Raponi M, Dossey L, Jatkoe T, Wu X, Chen G, Fan H, Beer DG: MicroRNA classifiers for predicting prognosis of squamous cell lung cancer. Cancer Res 2009, 69:5776-83.

6. Patnaik SK, Kannisto E, Knudsen S, Yendamuri S: Evaluation of MicroRNA Expression Profiles That May Predict Recurrence of Localized Stage I Non-Small Cell Lung Cancer after Surgical Resection. Cancer Res 2010, 70:36-45.

7. Bartel DP: MicroRNAs: genomics, biogenesis, mechanism, and function. Cell 2004, 116:281-297.

8. Bagga S, Bracht J, Hunter S, Massirer K, Holtz J, Eachus R, Pasquinelli AE: Regulation by let-7 and lin-4 microRNAs results in target mRNA degradation. Cell 2005, 122:553-563.

9. Lim LP, Lau NC, Garrett-Engele P, Grimson A, Schelter JM, Castle J, Bartel DP, Linsley PS, Johnson JM: Microarray analysis shows that some microRNAs downregulate large numbers of target mRNAs. Nature 2005, 433:769-773.

10. Rajewsky N: MicroRNA target predictions in animals. Nat Genet 2006, 38 S8-S13.

11. Lewis BP, Burge CB, Bartel DP: Conserved seed pairing, often flanked by adenosines, indicates that thousands of human genes are microRNA targets. Cell 2005, 120:15-20.

12. Calin GA, Sevignani C, Dumitru CD, Hyslop T, Noch E, Yendamuri $S$, Shimizu M, Rattan S, Bullrich F, Negrini M, Croce CM: Human microRNA genes are frequently located at fragile sites and genomic regions involved in cancers. Proc Natl Acad Sci USA 2004, 101:2999-3004.

13. Esquela-Kerscher A, Slack FJ: Oncomirs - microRNAs with a role in cancer. Nature Reviews Cancer 2006, 6:259-269.

14. Doleshal M, Magotra AA, Choudhury B, Cannon BD, Labourier E, Szafranska AE: Evaluation and validation of total RNA extraction methods for microRNA expression analyses in formalin-fixed, paraffin-embedded tissues. J Mol Diagn 2008, 10:203-11.

15. Shi L, Tong W, Goodsaid F, Frueh FW, Fang H, Han T, Fuscoe JC, Casciano DA: QA/QC: challenges and pitfalls facing the microarray community and regulatory agencies. Expert Rev Mol Diagn 2004, 4:761-777.

16. Shi $L$, Perkins RG, Fang $H$, Tong W: Reproducible and reliable microarray results through quality control: good laboratory proficiency and appropriate data analysis practices are essential. Curr Opin Biotechnol 2008, 19:10-8.

17. Shi L, Reid LH, Jones WD, Shippy R, Warrington JA, Baker SC, Collins PJ, de Longueville F, Kawasaki ES, Lee KY, Luo Y, Sun YA, Willey JC, Setterquist RA, Fischer GM, Tong W, Dragan YP, Dix DJ, Frueh FW, Goodsaid FM, Herman D, Jensen RV, Johnson CD, Lobenhofer EK, Puri RK, Scherf U, Thierry-Mieg J, Wang C, Wilson M, Wolber PK, Zhang L, Slikker W Jr, Shi L, Reid LH: The MicroArray Quality Control (MAQC) project shows interand intraplatform reproducibility of gene expression measurements. Nat Biotechnol 2006, 24:1151-1161.

18. Strauss E: Arrays of hope. Cell 2006, 127:657-9.

19. Wen Z, Wang C, Shi Q, Huang Y, Su Z, Hong H, Tong W, Shi L: Evaluation of gene expression data generated from expired Affymetrix GeneChip microarrays using MAQC reference RNA samples. BMC Bioinformatics 2010, 11(Suppl 6):S10.

20. Patterson TA, Lobenhofer EK, Fulmer-Smentek SB, Collins PJ, Chu TM, Bao W, Fang H, Kawasaki ES, Hager J, Tikhonova IR, Walker SJ, Zhang L, Hurban P, de Longueville F, Fuscoe JC, Tong W, Shi L, Wolfinger RD: Performance comparison of one-color and two-color platforms within the MicroArray Quality Control (MAQC) project. Nat Biotechnol 2006, 24:1140-50.

21. Gentleman RC, Carey VJ, Bates DM, Bolstad B, Dettling M, Dudoit S, Ellis B, Gautier L, Ge Y, Gentry J, Hornik K, Hothorn T, Huber W, lacus S, Irizarry R, Leisch F, Li C, Maechler M, Rossini AJ, Sawitzki G, Smith C, Smyth G, Tierney L, Yang JY, Zhang J: Bioconductor: Open software development for computational biology and bioinformatics. Genome Biology 2004, 5 R80.

22. $\mathrm{R}$ Development Core Team: $\mathrm{R}$ : A language and environment for statistical computing. R Foundation for Statistical Computing, Vienna, Austria; 2008.

doi:10.1186/1756-0500-4-424

Cite this article as: Dahlgaard et al.: Analytical variables influencing the performance of a miRNA based laboratory assay for prediction of relapse in stage I non-small cell lung cancer (NSCLC). BMC Research Notes 2011 4:424.

\section{Submit your next manuscript to BioMed Central and take full advantage of:}

- Convenient online submission

- Thorough peer review

- No space constraints or color figure charges

- Immediate publication on acceptance

- Inclusion in PubMed, CAS, Scopus and Google Scholar

- Research which is freely available for redistribution

Submit your manuscript at www.biomedcentral.com/submit
C Biomed Central 